\title{
Radiation-induced defects in GaN bulk grown by halide vapor phase epitaxy
}

Tran Thien Duc, Galia Pozina, Nguyen Tien Son, Erik Janzén, Takeshi Ohshima and Carl

Hemmingsson

\section{Linköping University Post Print}

\section{Tweet}

N.B.: When citing this work, cite the original article.

Original Publication:

Tran Thien Duc, Galia Pozina, Nguyen Tien Son, Erik Janzén, Takeshi Ohshima and Carl Hemmingsson, Radiation-induced defects in GaN bulk grown by halide vapor phase epitaxy, 2014, Applied Physics Letters, (105), 10, 102103.

http://dx.doi.org/10.1063/1.4895390

Copyright: American Institute of Physics (AIP) http://www.aip.org/

Postprint available at: Linköping University Electronic Press http://urn.kb.se/resolve?urn=urn:nbn:se:liu:diva-111755 


\section{AIP Applied Physics Letters}

\section{Radiation-induced defects in GaN bulk grown by halide vapor phase epitaxy}

Tran Thien Duc, Galia Pozina, Nguyen Tien Son, Erik Janzén, Takeshi Ohshima, and Carl Hemmingsson

Citation: Applied Physics Letters 105, 102103 (2014); doi: 10.1063/1.4895390

View online: http://dx.doi.org/10.1063/1.4895390

View Table of Contents: http://scitation.aip.org/content/aip/journal/apl/105/10?ver=pdfcov

Published by the AIP Publishing

\section{Articles you may be interested in}

Investigation of deep levels in bulk GaN material grown by halide vapor phase epitaxy

J. Appl. Phys. 114, 153702 (2013); 10.1063/1.4825052

Characterization of vacancy-type defects in heteroepitaxial GaN grown by low-energy plasma-enhanced vapor phase epitaxy

J. Appl. Phys. 112, 024510 (2012); 10.1063/1.4737402

Thermal stability of in-grown vacancy defects in GaN grown by hydride vapor phase epitaxy

J. Appl. Phys. 99, 066105 (2006); 10.1063/1.2180450

Radiation-induced electron traps in Al $0.14 \mathrm{Ga} 0.86 \mathrm{~N}$ by $1 \mathrm{MeV}$ electron radiation

Appl. Phys. Lett. 86, 261906 (2005); 10.1063/1.1977185

Strain-free bulk-like GaN grown by hydride-vapor-phase-epitaxy on two-step epitaxial lateral overgrown GaN template

J. Appl. Phys. 96, 799 (2004); 10.1063/1.1753073

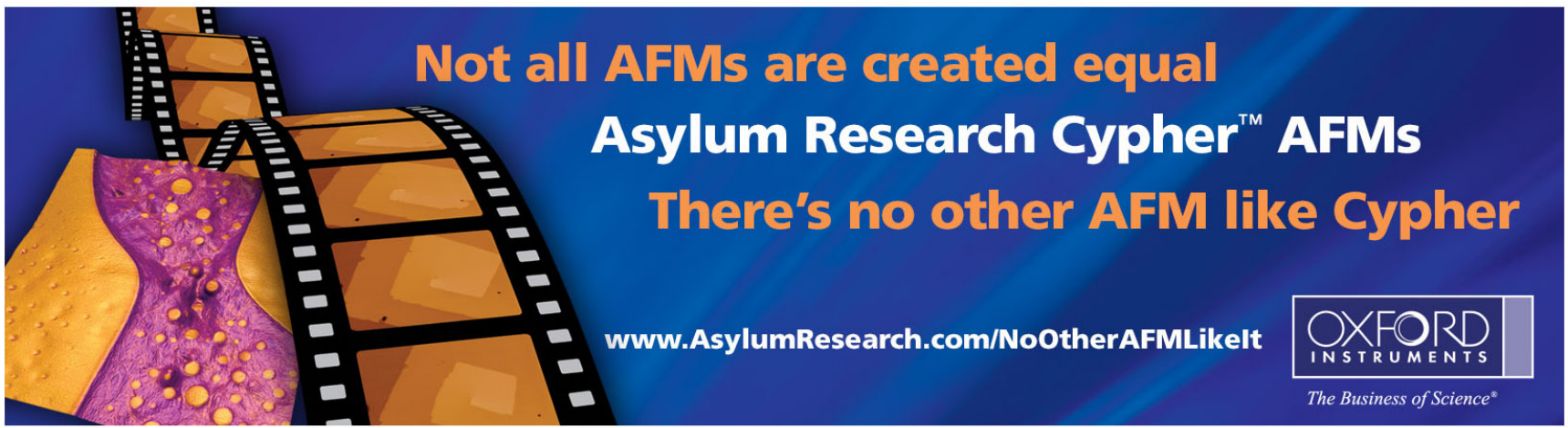




\title{
Radiation-induced defects in GaN bulk grown by halide vapor phase epitaxy
}

\author{
Tran Thien Duc, ${ }^{1}$ Galia Pozina, ${ }^{1}$ Nguyen Tien Son, ${ }^{1}$ Erik Janzén, ${ }^{1}$ Takeshi Ohshima, ${ }^{2}$ \\ and Carl Hemmingsson ${ }^{1}$ \\ ${ }^{1}$ Department of Physics, Chemistry and Biology (IFM), Linköping University, S-581 83 Linköping, Sweden \\ ${ }^{2}$ Japan Atomic Energy Agency (JAEA), Takasaki, Gunma 370-1292, Japan
}

(Received 8 July 2014; accepted 29 August 2014; published online 9 September 2014)

\begin{abstract}
Defects induced by electron irradiation in thick free-standing GaN layers grown by halide vapor phase epitaxy were studied by deep level transient spectroscopy. In as-grown materials, six electron traps, labeled D2 $\left(\mathrm{E}_{\mathrm{C}}-0.24 \mathrm{eV}\right), \mathrm{D} 3\left(\mathrm{E}_{\mathrm{C}}-0.60 \mathrm{eV}\right), \mathrm{D} 4\left(\mathrm{E}_{\mathrm{C}}-0.69 \mathrm{eV}\right), \mathrm{D} 5\left(\mathrm{E}_{\mathrm{C}}-0.96 \mathrm{eV}\right), \mathrm{D} 7$ $\left(\mathrm{E}_{\mathrm{C}}-1.19 \mathrm{eV}\right)$, and $\mathrm{D} 8$, were observed. After $2 \mathrm{MeV}$ electron irradiation at a fluence of $1 \times 10^{14} \mathrm{~cm}^{-2}$, three deep electron traps, labeled D1 $\left(\mathrm{E}_{\mathrm{C}}-0.12 \mathrm{eV}\right)$, D5I $\left(\mathrm{E}_{\mathrm{C}}-0.89 \mathrm{eV}\right)$, and D6 $\left(\mathrm{E}_{\mathrm{C}}-1.14 \mathrm{eV}\right)$, were detected. The trap D1 has previously been reported and considered as being related to the nitrogen vacancy. From the annealing behavior and a high introduction rate, the D5I and D6 centers are suggested to be related to primary intrinsic defects. (C) 2014 AIP Publishing LLC.

[http://dx.doi.org/10.1063/1.4895390]
\end{abstract}

With its outstanding optical and electrical properties such as a direct wide bandgap $(3.44 \mathrm{eV}$ at $300 \mathrm{~K})$, high breakdown field $\left(\sim 5 \times 10^{6} \mathrm{~V} \mathrm{~cm}^{-1}\right.$ at $\left.300 \mathrm{~K}\right)$, and high electron mobility $\left(\leq 1000 \mathrm{~cm}^{2} \mathrm{~V}^{-1} \mathrm{~s}^{-1}\right.$ at $\left.300 \mathrm{~K}\right),{ }^{1} \mathrm{GaN}$ has long been considered as the most promising material for optoelectronics and high-frequency power devices. In recent years, a rapid development of GaN-based devices has been made. However, due to the lack of native substrates, most of GaN-based electronics and optoelectronics used foreign substrates, such as sapphire and $\mathrm{SiC}$, which give rise to high dislocation densities, limiting and worsening the performance of devices. Using native substrates to reduce dislocation density is therefore highly desired. GaN bulk grown by halide vapor phase epitaxy $(\mathrm{HVPE})^{2,3}$ has become available only recently and knowledge on defects in the material is still rather poor. Identifying deep level defects and understanding their electronic structure are important for defect control and, hence, the success of device applications.

Electron irradiation is often used to create intrinsic defects in crystals in a controlled manner so that their deep energy levels can be conventionally studied by capacitance transient techniques such as deep level transient spectroscopy (DLTS). Several deep level defects induced by electron irradiation in GaN have been previously reported. ${ }^{4-9}$ Fang et al. found a deep defect level at $0.18 \mathrm{eV}$ below the conduction band in electron-irradiated $\mathrm{GaN}$, but its origin has not conclusively been identified. ${ }^{5}$ Polenta et al. ${ }^{9}$ did a detailed study of electron irradiated metalorganic chemical vapor deposition (MOCVD) grown n-type GaN Schottky diodes in the temperature range of $80-400 \mathrm{~K}$, revealing two severely overlapped DLTS peaks with the thermal activation energies of $\mathrm{E}_{\mathrm{C}}-0.06 \mathrm{eV}$ and $\mathrm{E}_{\mathrm{C}}-0.11 \mathrm{eV}$, respectively. Another observation by Goodman et al. suggested that there are at least three defects whose DLTS spectra overlapped with each other to form a broad peak with different activation energies $(0.06 \mathrm{eV}, 0.10 \mathrm{eV}, 0.20 \mathrm{eV})^{7}$

In this letter, we present results from DLTS studies of thick HVPE-grown GaN layers irradiated with electrons at an energy of $2 \mathrm{MeV}$ and a fluence of $1 \times 10^{14} \mathrm{~cm}^{-2}$. DLTS centers in as-grown and irradiated $\mathrm{GaN}$, and their annealing behavior at high temperatures (up to $1000^{\circ} \mathrm{C}$ ) are presented. It is known that the threading dislocation density (TDD) can influence the electrical properties and concentration of traps, ${ }^{10,11}$ therefore, we have used thick $(\sim 0.4 \mathrm{~mm})$ n-type GaN layers grown by $\mathrm{HVPE}^{2,3}$ with low TDD $\left(\sim 5 \times 10^{6} \mathrm{~cm}^{-2}\right.$ as determined by cathodoluminescence) for the study. The Ga-face was polished for improving the rectifying properties of the Schottky contacts. $1000 \AA$ thick Au dots with a diameter of $1.2 \mathrm{~mm}$ were used as Schottky contacts. The result from current versus voltage (IV) measurement showed a good rectifying property. For Ohmic contacts, silver paint was used on the backside of the samples. The samples were then irradiated with $2-\mathrm{MeV}$ electrons at a fluence of $1 \times 10^{14} \mathrm{~cm}^{-2}$. In order to avoid heating, the samples were put on a water-cooled copper plate during electron irradiation. The Schottky contacts were made prior the electron irradiation in order to avoid unintentional annealing of radiation-induced defects due to heating during the evaporating process. IV and capacitance versus voltage $(\mathrm{CV})$ measurements were performed to study the influence of irradiation on the rectifying characteristic and the freecarrier concentration in the samples. Diodes with a leakage current less than $10 \mu \mathrm{A}$ at a reverse bias of $-10 \mathrm{~V}$ were used for the DLTS measurements. Finally, the samples were annealed at the high temperature of $1000{ }^{\circ} \mathrm{C}$ in $\mathrm{N}_{2}$ ambient for $30 \mathrm{~min}$.

The DLTS data were collected by a homemade system using a $1 \mathrm{MHz}$ Boonton 7200 capacitance bridge and a $100 \mathrm{MHz}$ Tabor 8024 pulse generator. In our measurement, Schottky diodes were under a reverse bias of $-10 \mathrm{~V}$, the filling pulse amplitude was $10 \mathrm{~V}$, the filling pulse width was $10 \mathrm{~ms}$, and the temperature was in the range of $77-700 \mathrm{~K}$.

IV measurements show that the leakage current of Schottky diodes at room temperature before irradiation and after irradiation was about $-2 \mathrm{nA}$ at the reverse bias of $-10 \mathrm{~V}$. The IV measurement after irradiation is shown in the inset of Fig. 1. Thus, the leakage current was not affected by the irradiation. The depth profile from CV measurements after irradiation is slightly different in comparison with that in 


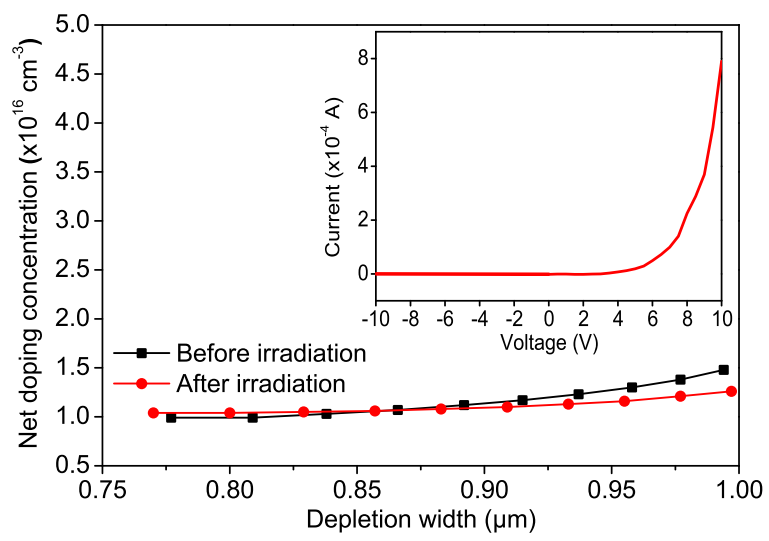

FIG. 1. Depth profile of net donor concentration of the Schottky diode on $\mathrm{n}-\mathrm{GaN}$ before irradiation (square) and after irradiation (circle). The inset shows IV characteristics of the Schottky diode after irradiation.

the as-grown sample (see Fig. 1). However, the change is very small and the average net donor concentration is approximately $1.4 \times 10^{16} \mathrm{~cm}^{-3}$ in both cases.

Fig. 2 illustrates the DLTS spectra of the sample measured before electron irradiation (Fig. 2(a)), after irradiation (Fig. 2(b)), and after irradiation and annealing at $1000{ }^{\circ} \mathrm{C}$ for 30 min (Fig. 2(d)). The DLTS peak amplitudes are proportional to the trap concentration which can be estimated by the expression ${ }^{12}$

$$
N_{T}=2 \times \frac{S(T) \times\left(N_{d}-N_{a}\right)}{C_{0}} \times \frac{r^{r /(r-1)}}{(1-r)},
$$

where $S(T)$ is the amplitude of the DLTS peak, $N_{d}-N_{a}$ is the net donor concentration, and $C_{0}$ is the background capacitance. The factor $r$ is the ratio $t_{2} / t_{1}$ where $t_{1}$ and $t_{2}$ are the capacitance sampling times. In order to take into account a small change of $N_{d}-N_{a}$ and $C_{\mathrm{o}}$ in the different cases, the spectra are scaled according to Eq. (1) where $r$ is equal to 8 by choosing $t_{2} / t_{1}=2$. After rescaling of the DLTS spectra, the absolute value of the peak amplitude corresponds to the trap concentration. By taking the difference between the scaled signal before and after irradiation, the increase of trap

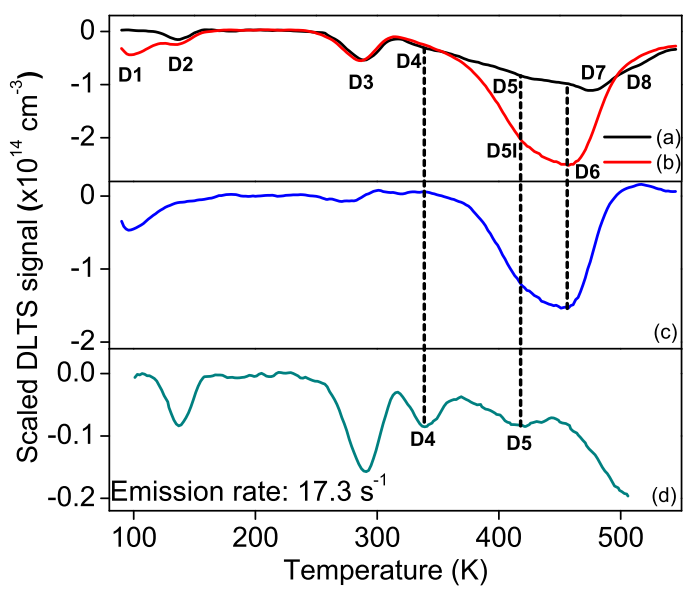

FIG. 2. The DLTS spectra after rescaling according to Eq. (1): (a) as-grown sample; (b) after electron-irradiated by $2 \mathrm{MeV}$ electron with a fluence of $1 \times 10^{14} \mathrm{~cm}^{-2}$; (c) the spectrum in irradiated sample after subtracting the signal measured before irradiation; and (d) the spectrum after annealing at $1000{ }^{\circ} \mathrm{C}$ for $30 \mathrm{~min}$ in $\mathrm{N}_{2}$ gas flow. concentration $\left(\Delta N_{T}\right)$ were determined, see Fig. 2(c). Before irradiation, we observe six traps labelled D2, D3, D4, D5, D7, and D8. The traps D2 and D3 form two distinct peaks while the traps D4, D5, D7, and D8 give rise to a broad band in the temperature range $340-550 \mathrm{~K}$ where peak D7 dominates the spectra. After electron irradiation, three traps, labelled D1, D5I, and D6, were observed. Peak D1 was not observed before irradiation. However, we cannot rule out that traps D5I and D6 are present before irradiation since they may be immersed by the strong D5 and D7 signal. Peak D1 is partly overlapping with peak D2, while peak D6 together with peak D5I dominates the spectra after irradiation. Most interestingly, we have observed that peak D8 was absent after irradiation.

In order to study the observed DLTS peaks in more detail, the difference between the DLTS signals before and after irradiation were evaluated, see Fig. 2(c). We observed that the concentration of traps D2, D3, and D4 does not change while the concentration of traps D5I and D6 increase significantly. As can be seen in the figure, the right shoulder of the broad peak does not show any signal from the trap D7 suggesting that the concentration of trap D7 is not affected by irradiation.

After annealing at $1000{ }^{\circ} \mathrm{C}$ for $30 \mathrm{~min}$ in nitrogen ambient (Fig. 2(d)), the traps D2, D3, D4, and D5 can still be observed, whereas traps D1, D5I, D6, and D7 are completely annealed out and in addition, peak D8, which was observed before irradiation, reappears. An interesting observation is a significant reduction in the concentration of the traps D5I and D6 after annealing. This means that the deep defect concentration in as-grown GaN can be improved by the heat treatment.

The activation energies and the intercept capture crosssection of the trap levels were obtained from an Arrhenius plot which illustrates the dependence of the thermal emission rate $e_{n}$ on the reciprocal temperature $1000 / T$ with $T$ being the temperature corresponding to the DLTS peak at different rate windows, as shown in Fig. 3. The slope of the plot gives information about the activation energy, and the capture cross section is determined from the intercept point when $T$ $\rightarrow \infty$. From the peak amplitudes, the concentration of traps was determined as in Ref. 13 where we have considered the

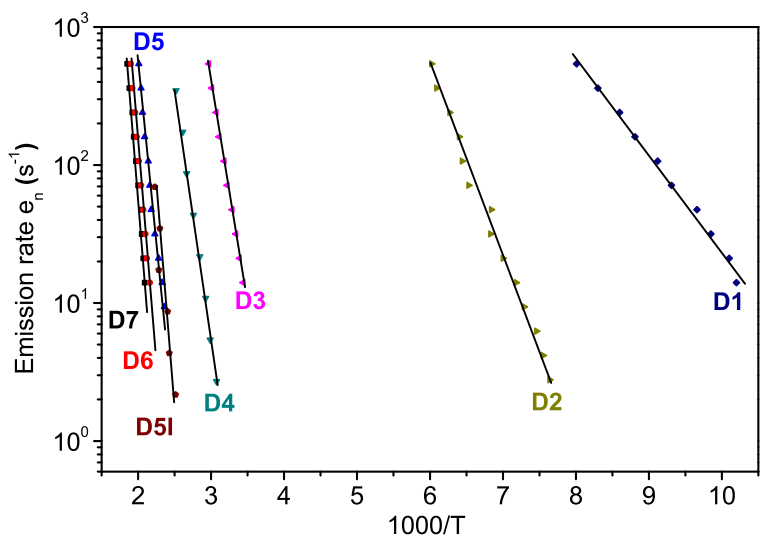

FIG. 3. Arrhenius plots of the electron emission rates for different deep levels observed in n-type GaN grown by HVPE before and after electronirradiation. 
TABLE I. The activation energy $\mathrm{E}_{\mathrm{a}}\left(\mathrm{E}_{\mathrm{C}}-\mathrm{E}_{\mathrm{t}}\right)$, the intercept capture cross section $\sigma_{\mathrm{int}}$ and the trap concentration $\mathrm{N}_{\mathrm{t}}$ deduced from the peak amplitudes before irradiation, after electron irradiation by $2 \mathrm{MeV}$ electrons with a fluence of $1 \times 10^{14} \mathrm{~cm}^{-2}$ and after annealing at $1000^{\circ} \mathrm{C}$ for $30 \mathrm{~min} . \Delta \mathrm{N}_{\mathrm{T}}$ is the increase of traps due to irradiation.

\begin{tabular}{lcccccc}
\hline \hline Trap level & $\mathrm{E}_{\mathrm{a}}(\mathrm{eV})$ & $\sigma_{\text {int }}\left(\mathrm{cm}^{2}\right)$ & $\mathrm{N}_{\mathrm{T}}\left(\mathrm{cm}^{-3}\right)$ Before irradiation & $\mathrm{N}_{\mathrm{T}}\left(\mathrm{cm}^{-3}\right)$ After irradiation & $\mathrm{N}_{\mathrm{T}}\left(\mathrm{cm}^{-3}\right)$ After annealing & $\Delta \mathrm{N}_{\mathrm{T}}\left(\mathrm{cm}^{-3}\right)$ After irradiation \\
\hline D1 & 0.12 & $1.7 \times 10^{-18}$ & 0 & $4.3 \times 10^{13}$ & 0 & $4.3 \times 10^{13}$ \\
D2 & 0.24 & $2.0 \times 10^{-16}$ & $1.5 \times 10^{13}$ & $\sim 1.5 \times 10^{13}$ & $8.4 \times 10^{12}$ & 0 \\
D3 & 0.60 & $2.5 \times 10^{-15}$ & $5.4 \times 10^{13}$ & $\sim 5.4 \times 10^{13}$ & $1.6 \times 10^{13}$ & 0 \\
D4 & 0.69 & $1.5 \times 10^{-15}$ & $\sim 2.4 \times 10^{13}$ & $\sim 2.4 \times 10^{13}$ & $8.5 \times 10^{12}$ & 0 \\
D5 & 0.96 & $3.0 \times 10^{-14}$ & $\sim 3.4 \times 10^{13}$ & $\ldots$ & 0 & $\ldots$ \\
D5I & 0.89 & $1.1 \times 10^{-15}$ & 0 & $\sim 1.0 \times 10^{14}$ & 0 & $\sim 1.2 \times 10^{14}$ \\
D6 & 1.14 & $7.7 \times 10^{-14}$ & 0 & $\sim 1.6 \times 10^{14}$ & 0 & 0 \\
D7 & 1.19 & $1.5 \times 10^{-13}$ & $\sim 5.3 \times 10^{13}$ & $\sim 5.3 \times 10^{13}$ & $\sim 1.9 \times 10^{13}$ & 0 \\
D8 & $\ldots$ & $\ldots$ & $\sim 1.7 \times 10^{13}$ & $\ldots$ & $\ldots$ \\
\hline \hline
\end{tabular}

influence of the free electron carrier tail. The obtained activation energies, capture cross sections and trap concentrations before and after irradiation and after annealing are presented in Table I.

Subtracting the signal measured before irradiation (Fig. 2(c)), we obtain the increase of the trap concentration $\left(\Delta N_{T}\right)$ after irradiation. However, since it was observed that peaks D5I and D6 were annealed out already during the high temperature DLTS measurements, the concentrations given for these levels are slightly underestimated.

Fig. 4 shows the concentrations of levels D1, D5I, and D6 extracted from sub-sequential DLTS measurements. The concentrations of traps show a tendency of decreasing to the values as in the as-grown sample where $N_{0}$ is the concentration of traps in the first scan and $N_{t}$ is the concentration of trap measured in each scan. As can be seen in the figure, the annealing process starts already at temperatures above $550 \mathrm{~K}$ for all defects. However, the process is slightly slower for trap D5I and the signals from the traps do not disappear completely until after annealing at $1000^{\circ} \mathrm{C}$ for $30 \mathrm{~min}$ (the fifth scan).

Peak D1 is introduced by electron irradiation and has been reported several times. ${ }^{5,7,9}$ Fang et al. ${ }^{5}$ suggested the level to be related to the $\mathrm{N}$ vacancy $\left(\mathrm{V}_{\mathrm{N}}\right)$. From simulation, this peak is suggested to consist of several overlapping levels.

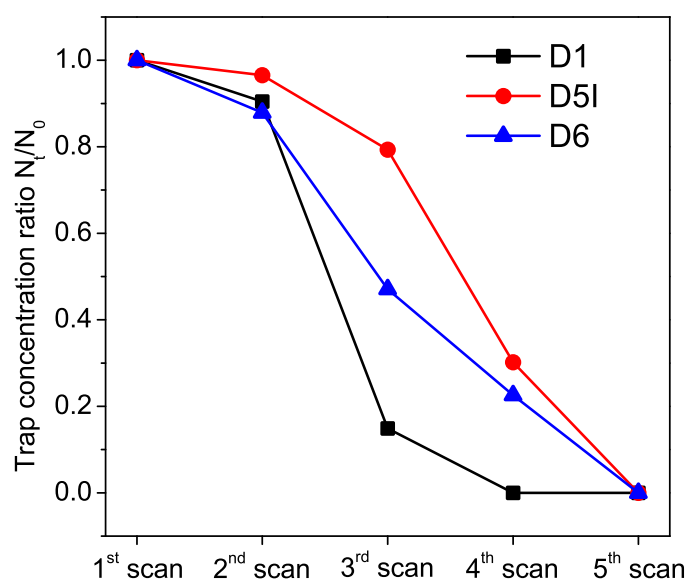

FIG. 4. The reduction in concentration of the traps D1 (square), D5I (round), and D6 (triangle) after each DLTS scan. The 1st scan was done in the temperature range $77-550 \mathrm{~K}$; the 2 nd scan in $77-600 \mathrm{~K}$, the $3 \mathrm{rd}$ and 4 th scans in $77-700 \mathrm{~K}$; the 5 th scan was performed after annealing at $1000^{\circ} \mathrm{C}$ for $30 \mathrm{~min}$ in $\mathrm{N}_{2}$.
Polenta et al. ${ }^{9}$ fitted this DLTS peak using two components with a thermal activation energy of 0.06 and $0.11 \mathrm{eV}$, respectively. In a later study on MOCVD grown GaN, Godmann et $a l^{7}{ }^{7}$ suggested that this peak is resulted from three overlapping levels. From numerical fitting, the activation energies were determined to Ec- $0.06 \mathrm{eV}, \mathrm{Ec}-0.10 \mathrm{eV}$, and Ec- $0.20 \mathrm{eV}$, respectively.

The trap D2 with an activation energy of $0.24 \mathrm{eV}$ detected before irradiation is commonly detected in asgrown GaN regardless of growth method. ${ }^{14-16}$ There have been different reports on this trap; however, its origin is still under debate. By using two kinds of precursors (TMGa and TEGa), Lee et al. ${ }^{17}$ proposed D2 to be carbon or hydrogen related defects. In a later study, Fang et al. suggested the peak to be related to the divacancy $\mathrm{V}_{\mathrm{N}}-\mathrm{V}_{\mathrm{Ga}} \cdot{ }^{18}$

The trap D3 at $\sim \mathrm{Ec}-0.60 \mathrm{eV}$ has been previously reported $^{10,11,16,19,20}$ and one of the suggested defect models is the $\mathrm{N}$ antisite $\left(\mathrm{N}_{\mathrm{Ga}}\right){ }^{19}$ However, later studies of electronirradiated HVPE-grown $\mathrm{GaN}^{21}$ ruled out the model of a simple intrinsic defect since no change of the concentration was observed after irradiation. This is in agreement with our observation. It was suggested that the defect is associated with some common impurity such as $\mathrm{Si}, \mathrm{O}$, or $\mathrm{C}$.

The signal from the trap D4 is very weak and has been previously observed in as-grown material. ${ }^{21,22}$ However, the concentration of the defect is unaffected by irradiation and thermally stable, which suggests that it is related to an impurity or possibly an impurity complex.

The trap D5 $(\mathrm{Ec}-0.96 \mathrm{eV})$ is observed before irradiation and after annealing at $1000^{\circ} \mathrm{C}$. Due to the overlap with D7, it is difficult to characterize the peak in detail. After irradiation, peak D5 is completely immersed by the strong peaks D5I with an activation energy of $0.89 \mathrm{eV}$ and by D6.

In Ref. 6, Goodman et al. studied electron irradiated MOCVD grown GaN and they observed a broad peak with an activation energy of $0.913 \mathrm{eV}$. By numerical fitting it was suggested that the peak consisted of at least 4 closely overlapping features coinciding with peaks D5 and D5I. However, no suggestion of its origin was given. In n-type HVPE-grown GaN irradiated by $25 \mathrm{GeV} \mathrm{H}^{+}$ions, Castaldini et $a l .{ }^{4}$ observed a level at $\sim \mathrm{Ec}-0.90 \mathrm{eV}$. The peak was severely overlapped with signals from other levels, hindering the identification. Based on the thermal stability at high temperatures, we suggest D5 to be associated with an isolated impurity or its associated complex. Judging from low 
annealing temperatures $(\sim 550 \mathrm{~K})$ and high introduction rate $\left(\sim 1.2 \mathrm{~cm}^{-1}\right)$, the D5I center may be related to a primary intrinsic defect.

Trap D6 at $\sim \mathrm{Ec}-1.14 \mathrm{eV}$ is only clearly observed after irradiation. However, due to overlapping with other peaks, we cannot rule out that the defect is already present before irradiation and so far there has not been any report about this trap. The defect has a high introduction rate $\left(\sim 1.5 \mathrm{~cm}^{-1}\right)$ and starts annealing out already at $550 \mathrm{~K}$, i.e., it has a similar introduction and annealing behavior as the trap D5I. Therefore, we suggest that the trap D6 may also be related to a primary intrinsic defect.

Trap D7 $(\mathrm{Ec}-1.19 \mathrm{eV})$ is observed before irradiation (Fig. 2(a)) and annealed out at $\sim 1000^{\circ} \mathrm{C}$ with the trap concentration being unaffected by irradiation. It has previously been observed by Ito et $a l .{ }^{23}$ but no defect model has been suggested for this trap. Since the concentration is unaffected by electron irradiation, the level is unlikely to be associated with a primary intrinsic defect. On the right shoulder of peak D7, we observe the weak peak D8 which has an interesting annealing behavior. After irradiation and a partial anneal due to the thermal DLTS scan (Fig. 2(b)), the signal disappeared, but then reappears after annealing at $1000^{\circ} \mathrm{C}$. The peak is observed at temperatures where intrinsic defects introduced by the electron irradiation become mobile ( $550 \mathrm{~K})$. Therefore, we tentatively suggest that the defect associated with the level D8 may form a complex with a primary intrinsic defect during the DLTS scan leading to the vanish of the signal in the DLTS spectrum. After annealing at $1000^{\circ} \mathrm{C}$ (Fig. 2(d)), the complex is disassociated and the level D8 is observed again. It was not possible to determine the activation energy and capture cross section of this level due to high leakage current at the high temperature but its peak position coincides with a level labeled E5 in Ref. 22.

In conclusion, freestanding bulk GaN was irradiated with $2 \mathrm{MeV}$ electrons at a fluence of $1 \times 10^{14} \mathrm{~cm}^{-2}$ at room temperature. In as-grown materials, six electron traps were observed for as-grown GaN, D2 $\left(\mathrm{E}_{\mathrm{C}}-0.24 \mathrm{eV}\right), \mathrm{D} 3$ $\left(\mathrm{E}_{\mathrm{C}}-0.60 \mathrm{eV}\right), \quad \mathrm{D} 4 \quad\left(\mathrm{E}_{\mathrm{C}}-0.69 \mathrm{eV}\right), \quad \mathrm{D} 5 \quad\left(\mathrm{E}_{\mathrm{C}}-0.96 \mathrm{eV}\right), \quad \mathrm{D} 7$ $\left(\mathrm{E}_{\mathrm{C}}-1.19 \mathrm{eV}\right)$, and $\mathrm{D} 8$ where $\mathrm{D} 4, \mathrm{D} 5, \mathrm{D} 7$, and $\mathrm{D} 8$ form a broad band in the temperature range of $350-600 \mathrm{~K}$. After electron irradiation, three traps were observed. Among these, the trap $\mathrm{D} 1\left(\mathrm{E}_{\mathrm{C}}-0.12 \mathrm{eV}\right)$ was associated to $\mathrm{N}$ vacancy and the traps D5I $\left(\mathrm{E}_{\mathrm{C}}-0.89 \mathrm{eV}\right)$ and $\mathrm{D} 6\left(\mathrm{E}_{\mathrm{C}}-1.14 \mathrm{eV}\right)$ were suggested to be related to primary intrinsic defects based on their high introduction rate and relatively low-temperature annealing behavior. The concentration of irradiation-induced traps (D1, D5I, D6) decreased already during the hightemperature DLTS scans and after annealing at $1000^{\circ} \mathrm{C}$ for 30 min in a $\mathrm{N}_{2}$ environment they were completely annealed out. The annealing process started at $\sim 550 \mathrm{~K}$; thus, primary defects are mobile already during the measurements. Most interestingly, after irradiation and a partial anneal due to the thermal DLTS scan, peak D8 disappeared and after annealing at $1000^{\circ} \mathrm{C}$, the peak reappeared. Thus, we suggest that the defect associated with peak D8 forms a complex with a primary intrinsic defect and the complex may be dissociated by annealing at $1000^{\circ} \mathrm{C}$. However, in order to verify this and understand the annealing process, further studies are necessary.

This work was supported by the Swedish Research Council (VR) and Swedish Energy Agency.

${ }^{1}$ M. E. Levinshtein, S. L. Rumyantsev, and M. S. Shur, Properties of Advanced Semiconductor Materials: GaN, AlN, InN, BN, and SiGe (John Wiley and Sons, New York, 2001), p. 2.

${ }^{2}$ C. Hemmingsson, P. P. Paskov, G. Pozina, M. Heuken, B. Schineller, and B. Monemar, Superlattices Microstruct. 40, 205 (2006).

${ }^{3}$ C. Hemmingsson and G. Pozina, J. Cryst. Growth 366, 61 (2013).

${ }^{4}$ A. Castaldini, A. Cavallini, and L. Polenta, J. Phys.: Condens. Matter 12, 10161 (2000).

${ }^{5}$ Z.-Q. Fang, J. W. Hemsky, D. C. Look, and M. P. Mack, Appl. Phys. Lett. 72, 448 (1998).

${ }^{6}$ S. Goodman, F. Auret, G. Myburg, M. Legodi, P. Gibart, and B. Beaumont, Mater. Sci. Eng. B 82, 95 (2001).

${ }^{7}$ S. A. Goodman, F. D. Auret, M. J. Legodi, B. Beaumont, and P. Gibart, Appl. Phys. Lett. 78, 3815 (2001).

${ }^{8}$ L. Ha, D. U. Lee, J. S. Kim, E. K. Kim, B. C. Lee, D. K. Oh, S.-B. Bae, and K.-S. Lee, Jpn. J. Appl. Phys., Part 1 47, 6867 (2008).

${ }^{9}$ L. Polenta, Z.-Q. Fang, and D. C. Look, Appl. Phys. Lett. 76, 2086 (2000).

${ }^{10}$ Z.-Q. Fang, D. C. Look, P. Visconti, D.-F. Wang, C.-Z. Lu, F. Yun, H. Morkoç, S. S. Park, and K. Y. Lee, Appl. Phys. Lett. 78, 2178 (2001).

${ }^{11}$ Y. Tokuda, Y. Matsuoka, H. Ueda, O. Ishiguro, N. Soejima, and T. Kachi, Superlattices Microstruct. 40, 268 (2006).

${ }^{12}$ D. K. Schroder, Semiconductor Material and Device Characterization (John Wiley \& Sons, New Jersey, 2006), p. 275.

${ }^{13}$ D. V. Lang, J. Appl. Phys. 45, 3023 (1974).

${ }^{14}$ C. D. Wang, L. S. Yu, S. S. Lau, E. T. Yu, and W. Kim, Appl. Phys. Lett. 72, 1211 (1998)

${ }^{15}$ W. Götz, N. M. Johnson, H. Amano, and I. Akasaki, Appl. Phys. Lett. 65, 463 (1994).

${ }^{16}$ P. Hacke, T. Detchprohm, K. Hiramatsu, N. Sawaki, K. Tadatomo, and K. Miyake, J. Appl. Phys. 76, 304 (1994).

${ }^{17}$ W. I. Lee, T. C. Huang, J. D. Guo, and M. S. Feng, Appl. Phys. Lett. 67, 1721 (1995).

${ }^{18}$ Z.-Q. Fang, D. C. Look, X.-L. Wang, J. Han, F. A. Khan, and I. Adesida, Appl. Phys. Lett. 82, 1562 (2003).

${ }^{19}$ D. Haase, M. Schmid, W. Kürner, A. Dörnen, V. Härle, F. Scholz, M. Burkard, and H. Schweizer, Appl. Phys. Lett. 69, 2525 (1996).

${ }^{20}$ D. Johnstone, S. Doğan, J. Leach, Y. T. Moon, Y. Fu, Y. Hu, and H. Morkoç, Appl. Phys. Lett. 85, 4058 (2004).

${ }^{21}$ D. C. Look, Z.-Q. Fang, and B. Claflin, J. Cryst. Growth 281, 143 (2005).

${ }^{22}$ T. T. Duc, G. Pozina, E. Janzén, and C. Hemmingsson, J. Appl. Phys. 114, 153702 (2013).

${ }^{23}$ T. Ito, M. Yoshikawa, A. Watanabe, and T. Egawa, Phys. Status Solidi 5, 2998 (2008). 